\title{
Improved Steroids Detection and Evidence for Their Regiospecific Decompositions using Anion Attachment Mass Spectrometry
}

Quentin Dumont, ${ }^{\dagger}$ Mariana Bárcenas, ${ }^{\dagger}$ Héloïse Dossmann, ${ }^{\dagger}$ Isabelle Bailloux, ${ }^{\ddagger}$ Corinne Buisson, ${ }^{\ddagger}$ Nathalie Mechin, ${ }^{\ddagger}$ Adeline Molina, ${ }^{\ddagger}$ Françoise Lasne, ${ }^{\ddagger}$ Nalaka S. Rannulu, ${ }^{\S, \#}$ and Richard B. Cole ${ }^{* \dagger}$

${ }^{\dagger}$ Sorbonne Universités, UPMC Univ Paris o6, CNRS, Institut Parisien de Chimie Moléculaire (IPCM), 4 place Jussieu 75252 Paris Cedex o5 France

‡ Agence Française de Lutte Contre le Dopage, Département des Analyses, 143 Avenue Roger Salengro, 92290 Châtenay-Malabry, France

${ }^{*}$ Dept. Of Chemistry, University of New Orleans, 2000 Lakeshore Dr., New Orleans, LA 70148

\section{SUPPLEMENTARY MATERIAL}

\section{Contents}

I- Reduction of pregnenolone-d4 hydroxyl-19

II- Experimental details

III- Structures of steroids under study

IV- Validation of the theoretical method

V- MS spectra

VI- Formation of the $m / z 302,301$, and 285 ions 


\section{I- Reduction of pregnenolone-d4 hydroxyl-19}

The reaction to reduce the double bond of pregnenolone- $\mathrm{d}_{4}$ hydroxyl-19 was carried out according to previously published procedures. ${ }^{1}$ Briefly, pregnenolone- $\mathrm{d}_{4}(16.7 \mathrm{mg}, 52 \mu \mathrm{mol})$ was placed in a $1.5 \mathrm{~mL}$ polypropylene tube and dissolved in $0.85 \mathrm{~mL}$ of a 2:1 v:v MeOH/THF mixture. The mixture was stirred by vortex until complete dissolution. $1.9 \mathrm{mg}$ of $\mathrm{NaBH}_{4}$ was added whereupon gas release was observed. The reaction mixture was agitated by vortex for $10 \mathrm{~min}$ at room temperature. $3.5 \mu \mathrm{L}$ of a $5 \% \mathrm{HCl}$ solution was added, triggering gas release; when gas formation halted, the reaction was terminated. The final concentration of the reduced steroid was 61.o mM. An analogous procedure was used to reduce the non-deuterated analog.

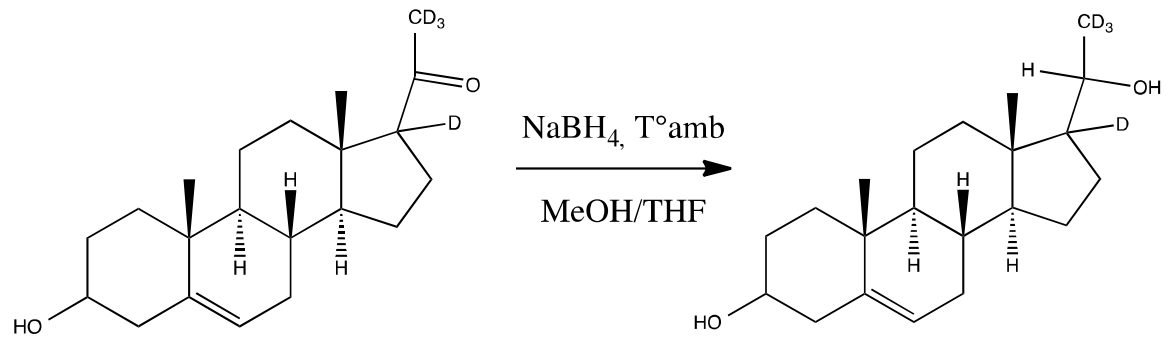

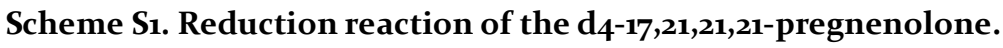

The reduction reaction is presented in Scheme $\mathbf{S 1}$. The stereochemistry at the newly formed chiral center of the final product is unknown, but is not critical for the purpose of the subsequent MS/MS experiments. High-resolution MS analysis of the final product was performed on a Solarix FT-ICR (Bruker Daltonics, Bremen, Germany). The following parameters were used for the analysis: ionization via an ESI source using direct infusion sample introduction at a flow rate of $2 \mathrm{~mL} / \mathrm{min}$, capillary voltage: $3.0 \mathrm{kV}$, DC plate offset: $500 \mathrm{~V}$, source accumulation time: $0.01 \mathrm{~s}$, ion accumulation time: $1.0 \mathrm{~s}$, ion cooling time: $0.01 \mathrm{~s}$, time of flight: $0.8 \mathrm{~ms}$, desolvation temperature: $200^{\circ} \mathrm{C}$. One MS spectrum corresponds to an average of 32 acquisitions. The analysis revealed $100 \%$ conversion for the reaction for both non-deuterated and $\mathrm{d} 4$ species.

\section{II- Experimental details}

Sample solutions were introduced into the mass spectrometer at a flow rate of $10 \mu \mathrm{L} / \mathrm{min}$, using nitrogen as both nebulizing and drying gas. The following instrumental parameters were used for all experiments: capillary $2.5 \mathrm{kV}$, sampling cone -20.0 V, extractor 4.o V, RF lens 1.o V, source temperature $80^{\circ} \mathrm{C}$, desolvation temperature $200^{\circ} \mathrm{C}$, cone gas flow $2 \mathrm{~L} / \mathrm{h}$, desolvation gas flow $200 \mathrm{~L} / \mathrm{h}$. All mass spectra were calibrated internally in negative ion mode over the range 50 $\leq m / z \leq 500$ and processed using MassLynx software (Waters). Displayed mass spectra represent the average of approximately 30 scans, whereas MS/MS spectra consist of approximately 120 scans.

Atmospheric pressure photoionization (APPI) experiments were carried out in an Orbitrap XL high resolution instrument (Thermo Scientific). The instrument conditions were: capillary temperature $275{ }^{\circ} \mathrm{C}$, vaporizer temperature $300{ }^{\circ} \mathrm{C}$, capillary voltage $8 \mathrm{~V}$, tube lens $67 \mathrm{~V}$ in positive ion polarity. The employed flow rate was $150 \mu \mathrm{L} / \mathrm{min}$ and the solvent composition was 9:1 v:v MeOH/H2O. In addition, for APPI, toluene was mixed in at $7.5 \mu \mathrm{L} / \mathrm{min}(5 \%$ of flow rate

\footnotetext{
${ }^{1}$ Stastna, E.; Cerny, I.; Pouzar, V.; Chodounska, H., Steroids 2010, 75 (10), 721-725.
} 
above). For the anion attachment MS experiments using ESI(-) on the Orbitrap, the conditions were: capillary temperature $220^{\circ} \mathrm{C}$; spray voltage $3.0 \mathrm{kV}$; capillary voltage $-7.5 \mathrm{~V}$ and tube lens 37.5 V. Flow rate was set at $100 \mu \mathrm{L} / \mathrm{min}$ using the same mobile phase as for APPI. All mass spectra are presented without smoothing and without background subtraction.

\section{III- Structures of steroids under study}<smiles>C[C@H]1CC2=CC(=O)CC[C@]2(C)C2CC[C@]3(C)[C@@H](CC[C@@]3(C)O)C21</smiles>

Calusterone $\mathrm{M}_{3}$<smiles>C[C@H]1CC2C[C@H](O)CC[C@]2(C)C2CC[C@]3(C)[C@@H](CC[C@]3(C)O)C21</smiles>

Calusterone- $\mathrm{M} \mathrm{M}_{4}$<smiles>C[C@]12C[C@@H](O)C3CCC4=CC(O)CC[C@]43C[C@@]1(C)CC[C@@]2(C)O</smiles>

Fluoxymesterone-M $\mathrm{M}_{2}$<smiles>C[C@]12CC[C@H]3C(CCC4Cc5nonc5C4)[C@@H]1CC[C@]3(C)O2</smiles>

Furazabol $\mathrm{M}_{5}$<smiles>C[C@]12Cc3nonc3CC1CCC1C2CC[C@@]2(C)C1C[C@H](O)[C@]2(C)O</smiles><smiles>CC[C@]1(O)CCC2C3CC[C@H]4CC(O)CC[C@H]4[C@H]3CC[C@]21C</smiles>

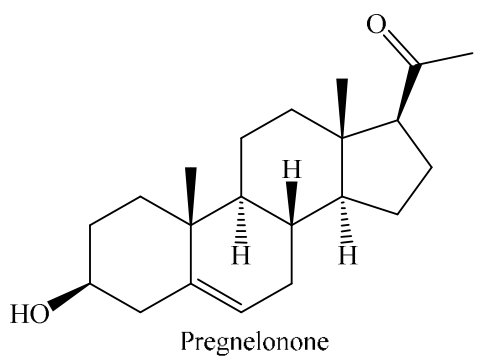

Furazabol-M<smiles>[R4][C@H]([CH])[CH][CH][CH]</smiles>

Scheme S2. Structure of all steroids studied in this work.

\section{IV- Validation of the theoretical method}

To test the validity of the method used in this work we have performed a comparison between calculated and experimental gas-phase acidities found in the literature for some organic molecules. Data are shown in Table S1. Agreement between experiment and theory is very good: calculated gas phase acidities show a standard deviation of about $5 \mathrm{~kJ} / \mathrm{mol}$.

Table S1. Calculated and experimental gas phase acidities $\Delta_{\text {acid }} G^{\circ}$ (in $\mathrm{kJ} / \mathrm{mol}$ ) of selected molecules.

\begin{tabular}{lcc}
\hline & \multicolumn{2}{c}{$\Delta_{\text {acid }^{\circ}} \mathbf{G}^{\circ} \mathbf{( k J / m o l )}$} \\
& Calculated $^{\text {a }}$ & Experimental $^{\text {b }}$ \\
\hline Acetic acid & 1428 & 1427 \\
4-Methyl-benzenemethanol & 1518 & 1523 \\
2,4-Dimethyl-3-pentanol & 1523 & 1523 \\
2,2-Dimethyl-1-propanol & 1534 & 1531 \\
i-Propyl alcohol & 1551 & 1543 \\
Phenol & 1431 & 1432 \\
Propanoic acid & 1422 & 1424 \\
Vinyl alcohol & 1459 & 1502
\end{tabular}




$\begin{array}{lcc}\text { Propen-2-ol } & 1461 & 1514 \\ \text { 4-Methyl-phenylmethyl alcohol } & 1517 & 1519 \\ \text { Phenylmethyl alcohol } & 1515 & 1520 \\ t \text {-Butyl } & 1528 & 1528 \\ \text { Cycloheptane } & 1544 & 1532 \\ \text { n-Propanol } & 1551 & 1546 \\ t \text {-Butanol } & 1546 & 1540 \\ \text { 1,3-Benzenediol } & 1426 & 1422 \\ \text { 4-Isopropylphenol } & 1420 & 1423\end{array}$

a $\mathrm{A}$ value of $-26.3 \mathrm{~kJ} / \mathrm{mol}$ is taken for the free energy of the proton as estimated by Ho and Coote (Ho, J.; Coote, M. L., First-principles prediction of acidities in the gas and solution phase. Wiley Interdiscip. Rev.: Comput. Mol. Sci. 2011, 1 (5), 649-66o).

${ }^{\mathrm{b}}$ Taken from NIST (P.J. Linstrom and W.G. Mallard, Eds., NIST Chemistry WebBook, NIST Standard Reference Database Number 69, National Institute of Standards and Technology, Gaithersburg MD, 20899, http://webbook.nist.gov, 07/09/14).

\section{V- MS spectra}
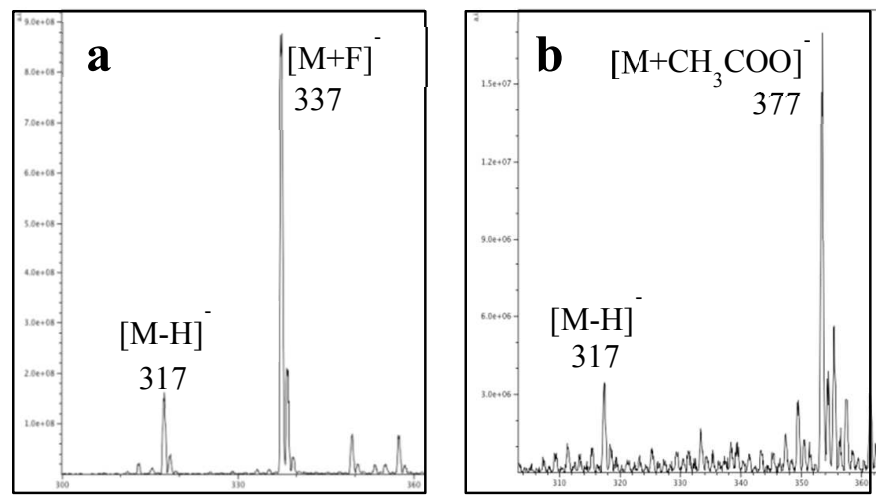

Figure S1. MS spectra of (a) (reduced pregnelonone $+\mathrm{NH}_{4} \mathrm{~F}$ ) and (b) (reduced pregnelonone+ $\mathrm{NH}_{4} \mathrm{AcO}$ ) solution.

\section{VI- Formation of $\mathrm{m} / \mathrm{z} 302,301$, and 285 product ions}

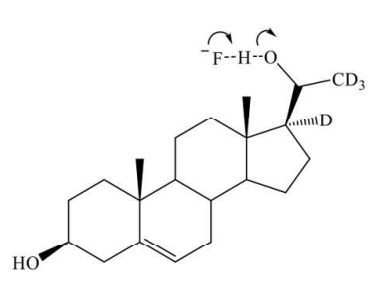

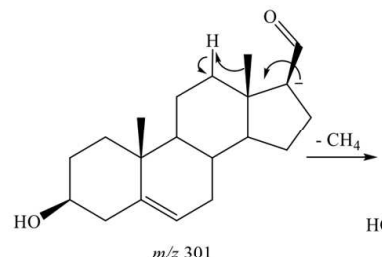<smiles>C[C@H]1CC[C@]2(C)C3CCC4C5CCC(C=O)=C5CCC4C3CC[C@]2(C)C1</smiles>

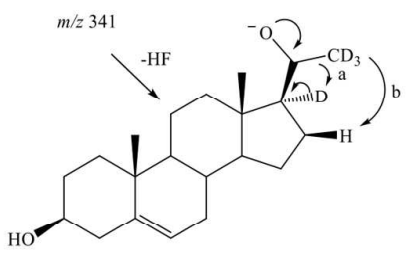<smiles>[GeH3]C1CC1</smiles>

$m / z 301$

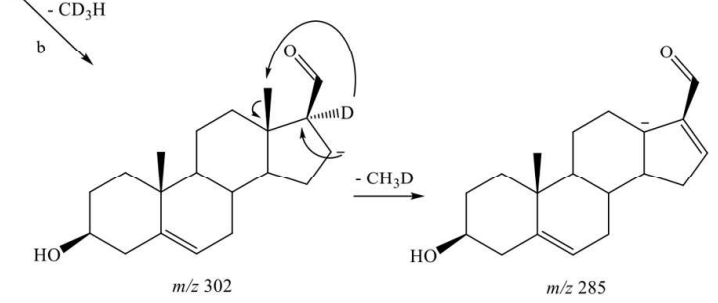

Scheme $S_{3}$. Proposed mechanism for the formation of the $\mathrm{m} / \mathrm{z} 302$, 301, and 285 product ions

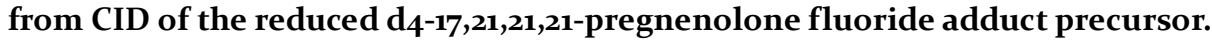

